\title{
Nutracêuticos imunomoduladores com potencial uso clínico para cães e gatos
}

\section{Immunomodulatory nutraceuticals with potential clinical use for dogs and cats}

\author{
Leandro Zaine ${ }^{1 *}$; Mariana Monti²; Ricardo Souza Vasconcellos ${ }^{3}$; \\ Aulus Cavalieri Carciofi ${ }^{4}$
}

\section{Resumo}

Tem-se observado o uso crescente de nutracêuticos em medicina veterinária, para auxiliar no tratamento clínico. Esta revisão teve como objetivo descrever alguns nutracêuticos que atuam sobre a imunidade de cães e gatos e levantar os possíveis benefícios como tratamento adjuvante para determinadas enfermidades. A ação de derivados de levedura tem sido bastante avaliada, especialmente da fração beta-glucano, um potente imunomodulador, com ação já demonstrada em cães e gatos, sendo benéfico no tratamento de algumas doenças. Os ácidos graxos poliinsaturados ômega-3, talvez os mais utilizados atualmente, podem trazer benefícios no tratamento de hipertensão, doenças renais e cardíacas, artrites, doenças autoimunes, doenças gastrintestinais e câncer. A vitamina E apresenta ação antioxidante e imunomoduladora, podendo auxiliar no tratamento de doenças dermatológicas e hepatobiliares. $\mathrm{O}$ uso de carotenoides, que tem ação semelhante à da vitamina $\mathrm{E}$, pode ser interessante por serem potentes antioxidantes, podem ajudar na melhora da resposta imune contra microrganismos e, também, na prevenção do aparecimento de tumores. Apesar de ainda serem necessários mais estudos clínicos para se entender os reais benefícios trazidos pela suplementação dos nutracêuticos em cada doença específica, a compreensão dos mecanismos de ação destes indica que são promissores para uso clínico.

Palavras-chave: Ácidos graxos poliinsaturados ômega-3, Beta-glucano, carotenoides, imunidade, vitamina $\mathrm{E}$

\begin{abstract}
The use of nutraceuticals in veterinary medicine is growing and is assumed that they could aid in clinical treatment. This review aims to describe some nutraceuticals that act on the immunity of dogs and cats and show the possible benefits as an adjuvant treatment for some diseases. The action of some yeast derivates as immunomodulators, especially the beta-glucan fraction, was already proved to occur in dogs and cats, being beneficial as an adjuvant therapy in many clinical conditions. Omega-3 polyunsatured fatty acids, possibly the mostly used nutraceuticals, can improve the condition in some diseases, such as hypertension, renal, cardiac, gastrointestinal and autoimmune diseases, arthritis and cancer. Vitamin $\mathrm{E}$ has antioxidant and immunomodulatory action and can aid in the treatment
\end{abstract}

\footnotetext{
${ }^{1}$ Médico Veterinário Autônomo, Dr. em Medicina Veterinária, Clínica Médica Veterinária, Universidade Estadual Paulista UNESP, Campus de Jaboticabal, SP. E-mail: lezaine@gmail.com

${ }^{2}$ Discente de Mestrado em Medicina Veterinária, Faculdade de Ciências Agrárias e Veterinárias, UNESP, Campus de Jaboticabal, SP. E-mail: mariana_814@hotmail.com

${ }^{3}$ Prof. do Dept ${ }^{\circ}$ de Zootecnia, Universidade Estadual de Maringá, UEM. Maringá, PR. E-mail: ricardo.souza.vasconcellos@gmail. com

${ }^{4}$ Prof. do Dept ${ }^{\circ}$ de Clínica e Cirurgia Veterinária, UNESP, Campus de Jaboticabal, SP. E-mail: aulus.carciofi@gmail.com

* Autor para correspondência
} 
of dermatologic and hepatobiliar conditions. The use of carotenoids, which have similar action to vitamin E, can be of interest for being potent antioxidants and might be helpful for enhancing immune response against microorganisms and also act preventing tumors. Despite it are still needed clinical trials to better understand the real benefits of nutraceuticals supplementation in each specific disease, the comprehension of the mechanisms by which they act indicates they are promising for clinical use.

Key words: Omega-3 polyunsatured fatty acids, beta-glucan, carotenoids, immunity, vitamin E

\section{Introdução}

A relação entre as pessoas e os animais de companhia tem mudado bastante nos últimos anos. Estes deixaram de ser apenas animais que viviam nos quintais e passaram a ser integrantes da família. Essa mudança levou a cuidados maiores com a saúde e, também, com a alimentação. A partir do aumento do uso de alimentos comerciais e nos cuidados para a prevenção e tratamento de doenças, notouse aumento da longevidade de cães e gatos. Com isto, têm sido relatadas maior ocorrência de doenças degenerativas e associadas ao envelhecimento, surgindo interesse e necessidade de se explorar o alimento como alternativa de promoção de saúde (CARCIOFI; GOMES, 2010). Além do papel fundamental da dieta em suprir a necessidade de energia e dos nutrientes essenciais, estuda-se a possibilidade desta promover a prevenção de doenças ou, até mesmo, auxiliar no tratamento das mesmas com o uso de nutracêuticos. Estes podem ser definidos como: "um alimento (ou parte de um alimento) que fornece benefícios médicos ou à saúde, incluindo a prevenção e/ou tratamento de uma doença" (BROWER, 1998) ou "uma substância produzida em uma forma purificada que, quando administrada oralmente a pacientes, tem como objetivo prover a eles os elementos para sua estrutura e função normal, para melhorar a saúde e o bem-estar" (BOOTHE, 1997).

Hoje se reconhece a importância do manejo alimentar para algumas doenças que induzem alterações metabólicas e funcionais específicas. A dieta é formulada de modo a apresentar composição nutricional que melhor se adeque às modificações metabólicas induzidas pela doença e é ferramenta importante, que vem sendo largamente empregada (HAND et al., 2010). Acredita-se que o uso de nutracêuticos, em associação a estas dietas específicas, possa resultar em benefícios adicionais aos pacientes. No entanto, para a maioria das substâncias, ainda existe pouca informação científica e muita controvérsia sobre sua eficácia e dosagem adequadas. Estas informações são especialmente escassas para cães e gatos, para os quais pouca pesquisa foi ainda produzida. Sendo assim, o objetivo desta revisão é apresentar alguns nutracêuticos com potencial efeito imunomodulador, discutir os dados científicos disponíveis para os mesmos e seus possíveis usos como terapia adjuvante para determinadas doenças.

\section{Derivados da parede celular de leveduras}

Muitos dos alimentos comerciais para cães e gatos produzidos no Brasil contêm derivados de levedura. Estes são incluídos argumentandose benefícios ao sistema imune e ação sobre a microbiota do trato gastrointestinal. Parecem auxiliar nos mecanismos de defesa, na seleção de microbiota gastrintestinal benéfica, na promoção da saúde intestinal e aglutinação de patógenos para que sejam eliminados. Para cães e gatos, no entanto, melhor compreensão de sua efetividade e mecanismos de ação é ainda necessária.

O modo de ação sobre a imunidade parece ser particular a cada um dos componentes específicos da parede celular das leveduras, por isso é importante se entender a sua composição. A parede celular de leveduras, como a Saccharomyces cerevisiae, é constituída principalmente por mananoproteínas, $\beta-1,3$ e $\beta-1,6$-glucano e quitina (LIPKE; OVALLE, 1998). Enquanto os beta-glucanos e a quitina são 
responsáveis pela rigidez da parede celular e definem sua forma, as manonoproteínas e sua porção de carboidrato (alfa-d-manano) são responsáveis pelo reconhecimento e interações célula-célula, interações com o meio e determinam a especificidade antigênica da levedura (RUIZ-HERRERA, 1992). Ambos os tipos de polissacarídeos constituintes principais da parede celular, os beta-glucanos e alfa-mananos, têm sido reconhecidos como capazes de modular o sistema imune por meio de interações específicas com várias células imunocompetentes (MEDZHITOV; JANEWAY JUNIOR, 2000). As superfícies mucosas, incluindo a gastrointestinal, nasal e broncoalveolar, representam parte do corpo do animal que está permanentemente exposta à agressão de patógenos e toxinas. Dessa forma, a adequada manutenção do sistema imune associado às mucosas representa uma tarefa crucial na proteção da saúde (TLASKALOVÁHOGENOVÁ et al., 2002; KOGAN; KOCHER, 2007). A ação imunomoduladora do beta-glucano tem sido relatada há mais de 40 anos (VETVICKA et al., 2008). Ele age por estimulação do sistema imune, desencadeando ações que parecem ter efeito benéfico contra uma variedade de bactérias, vírus, fungos e parasitas (HUNTER JUNIOR; GAULT; BERNER, 2002; MANTOVANI et al., 2008), imunoestimulação que pode levar a aumento na proteção contra infecções oportunistas (CROSS et al., 2001).

Além de poder auxiliar na resposta contra infecções, trabalhos descrevem a sua ação como adjuvante na terapia anti-tumoral. Em revisão sobre a relação do consumo beta-glucano de diversas fontes sobre a incidência e o tratamento de tumores em pessoas, Aleem (2013) conclui que seu consumo a longo prazo pode reduzir a incidência de neoplasias e quando usado como adjuvante na terapia pode ajudar a melhorar a resposta dos pacientes contra os efeitos colaterais da quimioterapia e radioterapia. Weitberg (2008) estudou o efeito do beta-glucano em pessoas com neoplasias malignas recebendo quimioterapia e concluiu que, além de ser bem tolerado, pode auxiliar a melhorar a hematopoiese. Além de melhorar a saúde, os pacientes que receberam o composto relataram ainda sensação de "bem-estar".

Recentemente, três trabalhos avaliaram os efeitos da administração oral de beta-1,3/1,6glucano sobre a imunidade de cães saudáveis. Stuyven et al. (2010) avaliaram o uso de betaglucano obtido de Saccharomyces cerevisiae, na forma de tabletes (225 mg por cão), por quatro semanas e encontraram efeitos sobre a imunidade humoral, com aumento de IgM sérica e diminuição de IgA no soro e nas mucosas. Haladová et al. (2009) também estudaram o efeito de beta-glucano sobre parâmetros imunológicos específicos e nãoespecíficos na espécie canina, com o uso de uma solução concentrada deste suplemento, a qual foi fornecida a filhotes de cães de várias raças. Observaram aumento de parâmetros imunológicos inespecíficos, tais como atividade funcional de fagócitos e linfócitos. Também foi notado aumento no título de anticorpos contra o vírus da raiva, após vacinação. No primeiro estudo de inclusão de betaglucano em alimento extrusado para cães, efeitos sobre a imunidade também foram notados (ZAINE, 2010). Foi verificado que animais que receberam esta substância tiveram aumento nas subpopulações linfocitárias de células $\mathrm{T}$ totais $\left(\mathrm{CD}^{+}\right), \mathrm{T}$ helper $\left(\mathrm{CD}^{+} \mathrm{CD} 4^{+}\right), \quad \mathrm{T}$ citotóxicos $\left(\mathrm{CD}^{+} \mathrm{CD} 8^{+}\right)$e linfócitos $\mathrm{B}\left(\mathrm{CD} 45^{+} \mathrm{CD} 21^{+}\right)$, aumento na resposta de hipersensibilidade tardia a inoculação de vacina polivalente e aumento na produção da citocina TNF- $\alpha$ em sobrenadante de cultura celular de mononucleares de sangue periférico.

Outros dois artigos recentes descreveram o uso de beta-glucano em cães doentes. Beynen e Legerstee (2010) estudaram a suplementação de beta-glucano em cães com osteoartrite e notaram que os animais tiveram melhora no grau de atividade e redução no grau de claudicação e dor. Os autores sugerem que o composto possa inibir a degradação do colágeno na matriz da cartilagem, com redução da inflamação e sensação de dor. Rychlik et al. (2013) avaliaram 
o uso de uma ração contendo beta-glucano em pacientes com doença inflamatória intestinal e encontraram melhora no quadro inflamatório após seis semanas de ingestão, com redução significativa dos sinais clínicos.

Foi encontrado somente um trabalho que avaliou a suplementação de beta-glucano em gatos. Animais que apresentavam quadro de gengivite receberam petiscos contendo beta-glucano. Os autores notaram redução da inflamação pela análise de citocinas e redução da perda de osso alveolar, apesar de não terem verificado melhora clínica no quadro, pois o edema e eritema não foram reduzidos pela suplementação (VERBRUGGHE et al., 2012).

Com relação à fração mananoligossacarídeos da parede celular de levedura, acredita-se que ela possa ter efeito prebiótico. Existe alguma confusão no estudo do composto em relação ao ingrediente empregado. Na maioria das situações não foi empregado mananoligossacarídeo, mas sim parede celular de levedura produzida por spray dry (CARCIOFI; GOMES, 2010). Como existem neste, além de mananoligossacarídeos, quantidades importantes de beta-glucano e mananoproteínas, não se pode identificar o composto que realmente apresenta efeito fisiológico nos estudos produzidos. Desta forma, na presente revisão, o composto será tratado como parede celular de levedura (PCL). Apesar de bem estudada em suínos e aves, poucos estudos estão disponíveis para cães e a PCL está incipientemente estudada em gatos (AQUINO et al., 2010). Esta não é digerida pelo organismo animal, sendo fermentada no intestino grosso propiciando formação de ácidos graxos de cadeia curta (CALABRO et al., 2013). Apesar de a literatura sugerir que a PCL altere positivamente a microbiota intestinal promovendo aumentos de lactobacilos e bifidobacteria e redução de salmonela e E. coli, (CARCIOFI; GOMES, 2010), os estudos em cães têm apresentados muita inconsistência de resultados, algum demonstrando tendência a este efeito (SWANSON et al., 2002b; GRIESHOP et al., 2004; BIGGS; PARSONS; FAHEY, 2007; MIDDELBOS; FASTINGER; FAHEY JUNIOR, 2007; YANG et al., 2008), enquanto outros não corroboraram este fato (STRICKLING et al., 2000; SWANSON et al., 2002a; WHITE et al., 2002; MIDDELBOS et al., 2007; MORALES-LÓPEZ et al., 2010).

Além de seu potencial efeito no intestino, a suplementação de PCL pode resultar em outros efeitos no sistema imune. Cães que consumiram este composto tiveram o aumento na concentração sérica de $\operatorname{IgA}$ e na porcentagem de linfócitos sanguíneos e quando consumido juntamente com frutoligossacarídeos encontrou-se também aumento de IgA ileal (SWANSON et al., 2002b). No trabalho de Gomes (2009), a quantificação imunofenotípica de linfócitos sanguíneos revelou aumento nas populações de linfócitos $\mathrm{CD}^{+}$e $\mathrm{CD} 21^{+}$. Outro estudo também demonstrou efeito sobre a imunidade celular, cães alimentados com dieta contendo PCL apresentaram aumento na resposta de hipersensibilidade tardia a uma vacina polivalente, indicando estimulação da função de linfócitos $\mathrm{T}$ auxiliares (ZAINE, 2010). Em outras espécies estes efeitos também já foram bastante relatados. Em leitões recém-desmamados, a suplementação com PCL levou à melhora da resposta imune específica e inespecífica, quando estes animais foram submetidos a desafios antigênicos (NOCHTA et al., 2009).

A limitação que se encontra, no entanto, é que, até o presente momento, não foram encontrados artigos que avaliaram o uso de PCL em situações clinicas, com cães e gatos doentes para se confirmar sua eficácia nesta condição. Apesar de se especular quanto aos potenciais benefícios, devido ao efeito prebiótico, as doenças podem alterar a microbiota e o sistema imune de forma que os efeitos demonstrados em animais saudáveis podem não ser os mesmos em pacientes com doenças gastrointestinais, sendo ainda necessários estudos específicos em animais doentes para validar e compreender sua efetividade (WHELAN, 2013). 
Ácidos graxos poliinsaturados ômega-3

Além de serem considerados nutrientes essenciais (NRC, 2006), outros benefícios do fornecimento de ácidos graxos poliinsaturados da família ômega-3 têm sido estudados. Confusão ainda se faz no segmento veterinário quanto às possíveis ações fisiológicas de dieta ou suplemento contendo estes compostos, não se distinguido adequadamente as ações dos ácidos graxos das famílias ômega-3 ou ômega-6. Dentro da família ômega-3, os ácidos graxos com ações fisiológicas são os ácidos alfalinolênico, eicosapentaenoico e docosaexaenoico. Cada um destes compostos possui ações fisiológicas diferentes e os ingredientes onde são encontrados não são os mesmos, o que deve ser considerado com cautela em seu uso prático.

Os ácidos graxos são cadeias de hidrocarbonetos com número variável de átomos de carbono, sendo classificados quanto ao número de carbonos na cadeia, o número de ligações duplas e a localização da primeira ligação dupla. É importante conhecer esta composição, pois a estrutura dos ácidos graxos está intimamente ligada aos seus efeitos no metabolismo celular (CARCIOFI; BAZOLLI; PRADA, 2002; FREEMAN, 2010). As famílias ômega-3 e ômega-6 são assim denominadas pela primeira dupla ligação da cadeia estar entre o terceiro e o quarto carbono, ou entre o sexto e o sétimo carbonos, respectivamente. Eles são considerados ácidos graxos essenciais, pois os cães e gatos não podem sintetizá-los e devem ser recebidos pela dieta (NRC, 2006; SIMOPOULOS, 2005). No organismo, estes ácidos graxos são incorporados à membrana celular, tendo efeitos sobre sua integridade e fluidez, atuando também na sinalização celular (TORREJON; JUNG; DECKELBAUM, 2007; CALDER, 2008).

Quando liberados das membranas celulares pelas fosfolipases, estes ácidos graxos são transformados pelas enzimas lipoxigenase e cicloxigenase no interstício, formando os eicosanoides prostaglandinas, leucotrienos e tromboxanos. Neste processo os ácidos graxos são substratos para estas enzimas e o tipo de mediadores inflamatórios gerados à partir da degradação de cada um deles é diferente, explicando os efeitos de seu consumo alimentar no status inflamatório e balanço imunológico dos animais (NRC, 2006). Foge ao escopo desta revisão apresentar detalhadamente o metabolismo e ações fisiológicas dos diferentes ácidos graxos ômega e seus derivados eicosanoides. Informações mais completas sobre o assunto podem ser encontradas nas referências citadas (DUNBAR; BAUER, 2002; SIMOPOULOS, 2005; TREVIZAN; KESSLER, 2009).

Dentro da família ômega-3, o primeiro ácido graxo da cadeia é o alfa-linolênico. Sua denominação molecular é C18:3 $\varpi 3$, o que indica que a molécula apresenta 18 átomos de carbono, 3 duplas ligações e que a primeira dupla ligação está no terceiro carbono (๘3). Pela ação das enzimas dessaturase e elongase os animais aumentam a estrutura química da molécula, sintetizando o ácido eicosapentaenoico (EPA; C20:5 ๓3) e o ácido docosaexaenoico (DHA; C22:6 ๗3). Esta conversão, no entanto, é limitada no cão e não ocorre no gato, de modo que para uma ação fisiológica correta deve-se suplementar na dieta destes animais carnívoros diretamente o EPA e o DHA (BAUER, 2011). Também denominados ácidos graxos poliinsaturados derivados, o EPA e o DHA somente estão presentes em tecidos animais e algumas algas, de modo prático óleos de peixe de águas marinhas frias são os ingredientes mais comumente disponíveis empregados para a suplementação destes compostos. Óleo ou semente de linhaça são por vezes empregados em alimentos industrializados ou rações. Estes contém apenas o ácido alfa-linolênico. Embora este ácido graxo apresente funções orgânicas, estas não se relacionam com imunomodulação e produção de eicosanoides, aspectos restritos ao EPA e DHA, motivo pelo qual não será abordado na presente revisão.

Efeito cardioprotetor, ação sobre o desenvolvimento neurológico, estrutura e função da retina, modulação da resposta inflamatória, controle de proteinúria e progressão da doença 
renal, alívio da dor associada a artrites, controle da inflamação cutânea em processos alérgicos e câncer estão entre os potenciais usos do óleo de peixe para cães (CARCIOFI; BAZOLLI; PRADA, 2002; FREEMAN, 2010; BAUER, 2011). As doses empregadas nos estudos são bastante variáveis e imprecisamente definidas. Recomendação prática de fornecimento de óleo de peixe tem sido de 1 grama para cada $4,5 \mathrm{~kg}$ de peso corporal, pois para exercerem efeito são necessários ao menos 50 a $60 \mathrm{mg}$ de EPA mais DHA por quilograma de peso corporal (FREEMAN, 2010). Em nossa experiência prática a aceitação do óleo de peixe é bastante variável e alguns cães podem passar a rejeitar o produto depois de algum tempo.

Nos alimentos comerciais as quantidades adicionadas são também muito variáveis. Vários produtos apresentam apenas linhaça na formulação como fonte de ômega-3, nesta condição a ausência de suplementação de EPA e DHA torna improvável algum efeito sobre a inflamação ou imunidade. Outra consideração é que o potencial terapêutico do EPA e DHA reside na capacidade destes ácidos graxos competirem uns com os outros pelas mesmas vias enzimáticas envolvidas na síntese dos eicosanoides. Como não existe interconversão ente as famílias ômega-6 e 3, eles são incorporados aos fosfolípides da membrana celular na dependência de sua concentração no alimento (REINHART, 1995). Uma vez liberados pela fosfolipases estes vão competir pela lipoxigenase e cicloxigenase e este balanço irá determinar a produção de mediadores mais ou menos inflamatórios. Assim, além da quantidade absoluta de EPA e DHA, sua relação no alimento com os ácidos graxos ômega-6, em especial o ácido araquidônico é também bastante importante e deve ser considerada na formulação do perfil de ácidos graxos do alimento (VAUGHN et al., 1994).

Os assuntos nos quais provavelmente existam mais estudos sobre a aplicação de EPA e DHA são nas doenças inflamatórias da pele. Vários estudos demonstraram a eficácia da suplementação destes ácidos graxos no manejo de doenças inflamatórias cutâneas de cães e gatos (MILLER; SCOTT; WELLINGTON, 1992; HARVEY, 1991; SCARFF; LLOYD, 1992; BOND; LLOYD, 1994; LOGAS; KUNKLE, 1994). SCOTT et al. (1997) relataram melhora de $8(44,4 \%)$, dentre 18 cães estudados com prurido atópicos, somente com a utilização de uma dieta comercial contento uma relação ômega6:ômega-3 de 5,5:1. Alguma imprecisão e confusão, no entanto, existe nos estudos iniciais, pois algumas vezes o tipo de ácido graxo não foi considerado, somente sua família, o que não é suficiente pela necessidade estrita de se fornecer para cães e gatos os ácidos graxos poliinsaturados derivados EPA e DHA.

A suplementação também se mostrou benéfica em pacientes cardiopatas. Em cães apresentando cardiomiopatia dilatada, o fornecimento de $25 \mathrm{mg}$ de EPA e $18 \mathrm{mg}$ de DHA por quilograma de peso corporal, em cápsulas de óleo de peixe, propiciou melhora no quadro de caquexia e redução da IL-1, sendo esta usada como um indicador do tempo de sobrevida dos pacientes, estando sua redução relacionada à maior taxa de sobrevivência (FREEMAN et al., 1998). Em cães com insuficiência renal crônica experimentalmente induzida, a administração de uma dieta contendo óleo de peixe, com dose equivalente a $760 \mathrm{mg}$ de EPA e DHA por quilograma de peso metabólico (peso corporal elevado a 0,75$)$, reduziu a proteinúria, preveniu a hipertensão glomerular e também reduziu a produção de eicosanoides pró-inflamatórios (BROWN et al., 1998). A suplementação também ajudou na resolução de um caso de hiperlipidemia em um cão e auxiliou na melhora de cães com osteoartrite (SCHENCK, 2006; ROUSH et al., 2010). Também se tem levantado a hipótese que esta suplementação seja benéfica para cães com doença inflamatória intestinal (IBD) e para animais com câncer (BAUER, 2011).

\section{Vitamina $E$}

O organismo sofre constantemente efeitos de espécies reativas de oxigênio (ROS), formadas 
como consequência natural da atividade metabólica e como parte da estratégia de atuação do sistema imunológico para destruir patógenos. Além disto, o corpo está exposto à ação constante de fontes exógenas que levam a formação de radicais livres. Estas moléculas instáveis prejudicam o organismo de diversas maneiras, seja por danos ao DNA, desnaturação proteica ou peroxidação dos lipídeos de membrana e proteínas celulares (HUGHES, 1999). A oxidação de lipídios é um exemplo típico de reação envolvendo radicais livres (ARAÚJO, 2001) e a velocidade da reação de oxidação depende do grau de insaturação na molécula do ácido graxo, assim, quanto maior o grau de insaturação, maior será a susceptibilidade à oxidação. Desta maneira, os ácidos graxos insaturados podem ser atacados quimicamente pelo radical livre, fazendo com que ocorra reação propagadora de auto-oxidação, na formação de novos radicais livres (BOOTH; McDONALD, 1992; ARAÚJO, 2001). Sendo as membranas biológicas ricas em ácidos graxos poliinsaturados (ZALATA; DEPUYDT, 1998; BAUMBER et al., 2000), estas tornam-se altamente sensíveis aos ROS (COMHAIRE; MAHMOUD et al., 1999). Afortunadamente, o organismo conta com muitos sistemas de defesa contra os danos causados pelos ROS, e estas defesas incluem enzimas dependentes de minerais (superóxido dismutase, catalase e glutationa peroxidase), proteínas com propriedades antioxidantes e os antioxidantes de baixo peso molecular, como o ácido ascórbico, a vitamina $\mathrm{E}$ e os carotenoides, além de outros compostos produzidos endogenamente ou adquiridos dos alimentos.

Os compostos antioxidantes podem ser classificados como enzimáticos (dismutases, catalases, peroxidases ou redutases) ou nãoenzimáticos (endógenos ou exógenos). São antioxidantes não-enzimáticos e produzidos endogenamente, o ácido lipoico, arginina, coenzima Q10, melatonina, ácido úrico, bilirrubina, complexos proteína-metais, ferritina, etc. Dentre antioxidantes adquiridos pela dieta, os mais comumente encontrados nos alimentos são a vitamina $E$, vitamina $\mathrm{C}$ (também produzida endogenamente), carotenoides, oligoelementos (cobre, ferro, zinco, selênio e manganês), flavonoides, dentre outros (PHAM-HUY; HE; PHAM-HUY, 2008).

O sistema imunológico é particularmente sensível aos efeitos do estresse oxidativo. As células deste sistema dependem fortemente da comunicação célula-célula, particularmente via receptores ligados à membrana, para trabalhar efetivamente. As membranas celulares são ricas em ácidos graxos poliinsaturados, os quais quando oxidados, prejudicam a fluidez de membrana e consequentemente a cascata de sinalização intracelular pela qual as células se comunicam (HUGHES, 1999).

Vitamina E é um termo genérico para os derivados tocol e tocotrienol que exibem atividade biológica do alfa-tocoferol. Todos os oito isômeros do tocoferol são isolados de alimentos de origem vegetal. O alfa-tocoferol tem grupos metil nos carbonos 5, 7 e 8 dos anéis fenólicos do 6-cromanol e seu sítio biologicamente ativo da molécula é o grupo 6-hidroxil no anel fenólico, o qual é capaz de doar hidrogênio na reação com os radicais livres. No metabolismo normal, em contato com radicais livres, o alfa-tocoferol é reversivelmente oxidado ao radical alfa-tocoferil cromanoxi e posteriormente reduzido por agentes como a glutationa e ácido ascórbico. Desta forma, é importante que as concentrações plasmáticas de ascorbato e glutationa também estejam adequadas. Outro caminho seguido pelo alfa-tocoferil cromanoxi é o seu metabolismo hepático e posterior eliminação via suco biliar (NRC, 2006).

A vitamina E é o maior antioxidante lipossolúvel no plasma, eritrócitos e demais tecidos, nos quais sua principal função é o sequestro de radicais livres para prevenir a oxidação dos ácidos graxos poliinsaturados das membranas celulares, grupos tióis de proteínas e ácidos nucléicos. A vitamina $\mathrm{E}$ também apresenta funções na modulação da síntese 
de prostaglandinas, regulação na síntese de proteína quinase e síntese da xantina oxidase, no entanto, a função antioxidante parece ser a principal (NRC, 2006).

A quantidade de vitamina $E$ exigida nos alimentos depende da taxa de produção de radicais livres pelo organismo, da composição de ácidos graxos poliinsaturados na dieta e outros compostos dietéticos como o selênio, por exemplo, necessário para a síntese de glutationa peroxidase (NRC, 2006). Apesar da recomendação da Association of American Food Control Officials (AAFCO, 2010) mínima de 50 UI de alfa-tocoferol por quilograma de alimento (UI/kg), demonstrou-se que a utilização de $100 \mathrm{UI} / \mathrm{kg}$ de alimento foi insuficiente para prevenir a formação de lipofuscina, um pigmento celular típico do envelhecimento celular, em filhotes de cães alimentados com dietas contendo elevadas concentrações de ácidos graxos poliinsaturados. As informações sobre toxidade da vitamina E são pouco estudadas em cães, no entanto, sabe-se que a utilização de elevadas concentrações nos alimentos prejudica a absorção das vitaminas A e K, apesar de estudos com dosagens extremamente elevadas em cães terem falhado em demonstrar efeitos tóxicos. Em humanos, a ingestão de aproximadamente 75 UI/kg melhorou a condição de saúde de pacientes (DEVARAJ et al., 2007).

Jewell et al. (2000) estudaram os efeitos da suplementação dietética de alfa-tocoferol em cães e gatos sobre indicadores da lipoperoxidação (malondialdeído e 4-hidroxinonenal) e verificaram que as concentrações dietéticas de 445 UI/ $\mathrm{kg}$ e $540 \mathrm{UI} / \mathrm{kg}$ de alimento para cães e gatos, respectivamente, foram eficientes em reduzir a formação destes compostos nas duas espécies. Os níveis de alfa-tocoferol em alimentos comerciais para cães e gatos variam entre aproximadamente 50-1100 UI/kg de alimento, embora a maior parte apresente concentrações inferiores a $100 \mathrm{UI} / \mathrm{kg}$.

Cães adultos suplementados com um blend de antioxidantes, em dosagens quatro vezes superiores às recomendadas de vitamina $\mathrm{E}$ em alimentos para animais adultos (AAFCO, 2010), apresentaram elevação nas concentrações séricas de taurina e vitamina $\mathrm{E}$, que foram associadas com menor dano sofrido ao DNA, melhora na resposta vacinal e melhor atividade antioxidante do plasma sanguíneo (HEATON et al., 2002).

A absorção intestinal de alfa-tocoferol após a ingestão oral em humanos varia entre 51-86\% (TRABER etal., 1998). No entanto, a absorção parece estar relacionada também com a concentração na dieta, uma vez que se correlacionam inversamente. Por este motivo, alguns autores verificaram que a ingestão de elevadas dosagens de alfa-tocoferol durante teste de tolerância à vitamina $\mathrm{E}$ em humanos, foram capazes de elevar apenas em três vezes as concentrações plasmáticas deste composto. $\mathrm{O}$ transporte plasmático da vitamina $\mathrm{E}$ é feito pelas lipoproteínas e o fígado apresenta papel central na regulação das suas concentrações plasmáticas. A proteína transferidora de tocoferol (PTT) tem o papel de seletivamente ligar as diferentes formas de tocoferol (alfa, beta, delta, gama, entre outros) nas lipoproteínas para seu transporte para os tecidos, para finalmente exercer sua atividade biológica. Desta forma, as concentrações plasmáticas e atividade biológica desta vitamina dependem da sua forma química e capacidade de transferência das PTTs (TRABER et al., 1998). Traber et al. (1998) suplementaram em humanos doses elevadas, de até aproximadamente $10.000 \mathrm{UI}(10 \mathrm{~g})$, e verificaram aumento nas concentrações desta vitamina no plasma, evidenciando a necessidade de se conhecer as tolerâncias e respostas biológicas de indivíduos em diferentes fases da vida. Devaraj et al. (2007) verificaram redução nas concentrações de $\mathrm{F}_{2}$ isoprostanos urinários (produto final da oxidação do ácido araquidônico liberado da membrana celular) e proteína-C reativa em humanos hospitalizados, com a suplementação de 1.200UI de alfa-tocoferol.

Dentre os benefícios conhecidos com a utilização de vitamina E, Marangon et al. (1999) verificaram 
que a suplementação de indivíduos saudáveis com alfa-tocoferol reduziu a lipoperoxidação, vista pela redução na produção de malondialdeído, $\mathrm{F}_{2}$ isoprostanos e retardo na oxidação das lipoproteínas de baixa densidade (LDL). No entanto, a oxidação protéica parece não ter sido reduzida com a suplementação desta vitamina, sendo necessária a suplementação com outros tipos de antioxidantes para a atuação neste tipo de oxidação.

São poucos os trabalhos encontrados com vitamina $E$ na nutrição clínica de cães e gatos, apesar de ser relatado seu possível uso como tratamento adjuvante para doenças dermatológicas e hepatobiliares (VANDEWEERD; CAMBIER; GUSTIN, 2013). A suplementação desta vitamina em pacientes com doença inflamatória hepática crônica propiciou aumento no alfa-tocoferol sérico e hepático e uma possível melhora sobre o status oxidativo (TWEDT; WEBB; TETRICK, 2003). Kapun et al. (2013) demonstraram que em cães com dermatite atópica, os níveis plasmáticos de vitamina E estão diminuídos, sugerindo que sejam feitos estudos para avaliar a suplementação de vitamina E para animais com tal doença. Behera et al. (2011) verificaram um efeito positivo da associação de vitamina E, selênio e ivermectina no tratamento de sarna sarcóptica, relatando resultados melhores do que no tratamento somente com ivermectina.

\section{Carotenoides}

Os carotenoides são um grupo de pigmentos que atuam em diversas e importantes funções em todos os organismos vivos, sendo as funções principais antioxidante e imunorreguladora (DOMONKOS et al., 2013). Foram isolados mais de 600 compostos carotenoides diferentes advindos naturalmente de plantas e outros organismos pigmentados. Os principais representantes dos carotenoides são os carotenos precursores da vitamina A e o licopeno (HUGHES, 1999; CASTRO, 2008). As xantofilas são sintetizadas a partir dos carotenos, por meio de reações de hidroxilação e epoxidação. O beta- caroteno e o licopeno são exemplos de carotenos, enquanto a luteína e a zeaxantina são xantofilas (AMBRÓSIO; CAMPOS; FARO, 2006). O betacaroteno é o mais abundante em alimentos e o que apresenta a maior atividade de vitamina A. Tanto os carotenoides precursores de vitamina A como os não precursores, como a luteína, a zeaxantina e o licopeno, parecem apresentar ação protetora contra o câncer, sendo que os possíveis mecanismos de proteção são por intermédio do sequestro de radicais livres, modulação do metabolismo do carcinoma, inibição da proliferação celular, aumento da diferenciação celular via retinoides, estimulação da comunicação entre as células e aumento da resposta imune (STAHL; SIES, 2003; CHEW; PARK, 2004; AMBRÓSIO; CAMPOS; FARO, 2006).

A ação imunorreguladora dos carotenoides está altamente correlacionada com a sua ação antioxidante. Os linfócitos, responsáveis pela imunidade adquirida, por serem células muito ativas, geram constantemente ROS (CHEW; PARK, 2004). As propriedades antioxidantes dos carotenoides são estudadas devido à estreita relação entre a ingestão destes compostos e redução na incidência de câncer em algumas populações humanas (HUGHES, 1999).

Estudos sobre o papel dos carotenoides na função imune demonstram que atuam na estimulação da imunidade inata; sobre a resposta imune celular; na produção de imunoglobulinas; regulam o sistema imune adaptativo e a hematopoiese. Também tem sido demonstrada a atuação dos carotenoides na imunidade tumoral (PARK; CHEW; WONG, 1998; CHEW; PARK, 2004).

Dos carotenoides, o beta-caroteno é o mais estudado e tem um importante papel na modulação da imunidade e promoção da saúde para muitas espécies. Os primeiros estudos demonstravam efeitos antibacterianos e protetores contra infecções. Recentemente, estudos em humanos revelam que dietas ricas em beta-caroteno reduzem a incidência de cânceres de pulmão e mama 
(MASSIMINO et al., 2003) através dos seus efeitos antitumorais. As doses de beta-caroteno empregadas nos estudos em humanos variam de $15-180 \mathrm{mg} /$ dia e tem sido relatados efeitos sobre as subpopulações linfocitárias, especialmente de linfócitos T auxiliares (HUGHES, 1999) e também em células natural killers (SANTOS et al., 1996). A imunidade mediada por células é iniciada por células apresentadoras de antígeno, das quais os monócitos fazem parte. Estas células apresentam em sua superfície a molécula do Complexo de Histocompatibilidade Principal de classe-II (MHC-II) o qual está diretamente relacionado à responsividade do sistema imunológico. Hughes (1999) investigaram pacientes humanos suplementados com $90 \mathrm{mg} /$ dia de beta-caroteno contra um grupo controle e verificaram aumento significativo na expressão de MHC-II e também da molécula de adesão intercelular I (ICAM-I), a qual é importante para promover a adesão entre as células na resposta imune primária.

Em cães, o beta-caroteno é efetivamente absorvido no intestino. Nesta espécie, a suplementação de 20 ou $50 \mathrm{mg} / \mathrm{animal} /$ dia de betacaroteno (aproximadamente 200-500 mg/kg de alimento) propiciou maior número de células $\mathrm{CD} 4^{+}$ e maior relação $\mathrm{CD}^{+}: \mathrm{CD}^{+}$, maior concentração de IgG plasmática e melhor resposta vacinal e resposta antigênica, quando comparados aos grupos que receberam menores doses de beta-caroteno ou não suplementados (CHEW et al., 2000). Em outro estudo foi verificada melhora na resposta imune humoral e celular em cães sênior após a suplementação de beta-caroteno (MASSIMINO et al., 2003).

Nas cadelas, o beta-caroteno pode auxiliar na síntese do estrógeno e da progesterona, hormônios envolvidos nas mudanças de comportamento durante o cio e na preparação do útero para a possível gestação. É possível que a dieta com betacaroteno possa melhorar a função reprodutiva nos cães (WENG et al., 2000).
A luteína é um carotenoide natural antioxidante encontrado em plantas e microrganismos e possui ação antioxidante, protegendo a membrana das células contra danos oxidativos (MASSIMINO et al., 2003). A luteína está presente nos olhos, soro, pele, cérvix, cérebro e mamas (BIAN et al., 2012).

Em cães, é absorvida pela dieta e incorporada por linfócitos. A suplementação nessa espécie resultou em aumento da resposta imune mediada por células e da imunidade humoral. Foi demonstrado efeito sinérgico positivo da luteína, beta-caroteno e vitamina $\mathrm{E}$ na resposta imune. Cada nutriente interagiu em diferentes partes do sistema imune, mostrando que a combinação possui efeito mais forte e efetivo do que a suplementação de apenas um ingrediente (MASSIMINO et al., 2003).

A luteína possui mecanismos consistentes de ação inibindo o crescimento de tumor mamário em ratos. Nos animais que foram suplementados demonstrou-se uma redução da incidência do desenvolvimento de tumor, em uma fase inicial (PARK; CHEW; WONG, 1998).

A ação antitumoral e imunomoduladora da luteína sugere também um envolvimento na apoptose, angiogênese e regulação gênica. Mostrou-se que a suplementação da luteína na dieta diminuiu a apoptose nos leucócitos sanguíneos, em ratos (CHEW; PARK, 2004). Por outro lado, a apoptose nas células tumorais aumentou, sugerindo o aumento na morte de células tumorais. Sumantran et al. (2000), similarmente mostrou in vitro que a luteína induz apoptose em células tumorais humanas.

Estudo feito por Kim et al. (2000a), mostrou que a luteína na dieta modula a resposta imune humoral e celular em gatos após quatro semanas de suplementação. Estudo anterior demonstrou seu efeito na resposta proliferativa de linfócitos a mitógenos em ratos (CHEW; WONG; WONG, 1996). Outro estudo de Kim et al. (2000b) com cães conclui que a luteína também aumentou a resposta de anticorpos a vacina, aumentou as populações de 
células T auxiliares e T citotóxicas e a expressão das moléculas do MHC de classe II.

Pesquisas utilizando-se de luteína mostram que é benéfica para a performance visual (KVANSAKUL et al., 2006; SHANMUGAM et al., 2011). Dentre 600 carotenóides, tem se destacado pela sua habilidade reduzir o risco de ocorrência de doenças oculares, como por exemplo, a degeneração macular senil (BIAN et al., 2012). Exerce também papel no auxílio à redução de riscos de catarata (BROWN et al., 1999; CHASAN et al., 1999), na saúde cardiovascular (DWYER et al., 2001) e na saúde da pele (STAHL et al., 2000).

A astaxantina é um carotenoide com potente atividade antioxidante. A microalga Haematococcus pluvialis é a maior produtora natural deste pigmento carotenoide responsável pela coloração avermelhada na carne de camarões, salmões e outros organismos (CAVALHEIRO et al., 1999).

Estudos mostram que a utilização desta substância na dieta traz benefícios como redução no estresse oxidativo das células (CHEW; PARK, 2004), redução dos danos no DNA em cães (CHEW et al., 2011), alta atividade antitumoral contra o fibrossarcoma (CHEW; PARK, 2004) e supressão de infecções bacterianas (BENNEDSEN et al., 1999).

Park et al. (2011) por sua vez, demonstraram que gatos apresentam melhor absorção oral da astaxantina do que cães, o que pode sugerir maior efetividade deste nutracêutico nessa espécie.

Como um antioxidante, a astaxantina parece ser o carotenoide mais efetivo para reduzir a peroxidação lipídica e o estresse oxidativo in vitro e in vivo (BARROS et al., 2001). Esses dados corroboram o estudo de Chew et al. (2011), em que a suplementação de astaxantina reduziu a peroxidação lipídica em cães. Astaxantina também reduz danos no DNA em humanos e cães e atenua os danos musculares durante o exercício em ratos (AOI et al., 2003). Sugere-se que possua efeito anti- inflamatório, por levar à diminuição na concentração da proteína $\mathrm{C}$ reativa em humanos (PARK et al., 2010a) e cães (CHEW et al., 2011).

Como imunorregulador, a astaxantina ajuda a melhorar a função imune através do aumento das células produtoras de anticorpos e do reforço ao sistema imune pela estimulação de células T. Seu uso pode diminuir o risco de doenças infecciosas, ajudando os animais a se manterem saudáveis (PARK et al., 2010b).

\section{Considerações finais}

A compreensão dos mecanismos pelos quais os nutracêuticos atuam sobre a imunidade é importante para se considerar o seu uso potencial em situações clínicas em que a resposta imune se encontra alterada. No entanto, somente com estudos clínicos específicos para cada doença é que se pode afirmar que seu uso seja realmente benéfico.

O uso, principalmente, de ácidos graxos poliinsaturados ômega-3 já vem sendo amplamente feito na clínica de cães e gatos e abre-se a possibilidade para seu uso como tratamento adjuvante em outras situações.

Destaca-se o potencial do uso de beta-glucano, substância há muito usada em medicina humana, que já foi provada como imunomoduladora em cães e gatos e agora começa a ser usada para auxiliar no tratamento de algumas enfermidades. Muitos trabalhos mostram seus benefícios no tratamento de pacientes humanos com câncer, abrindo a possibilidade que estudos com essa doença também sejam feitos em medicina veterinária.

A vitamina E e os carotenoides, com ação principalmente antioxidante, também podem atuar sobre a imunidade, podendo auxiliar em algumas situações clínicas. Especialmente, no caso da vitamina $E$ já se tem evidências que pode ser efetiva no tratamento de doenças hepáticas e dermatológicas. 
Uma questão recorrente é sobre qual seriam os benefícios desta suplementação em alimentos para animais saudáveis. Estudos em longo prazo seriam necessários para verificar se o uso de nutracêuticos poderia ajudar na prevenção do aparecimento de algumas enfermidades. No entanto, por não se observarem efeitos adversos da suplementação destes nutracêuticos nas doses usualmente preconizadas e pela possibilidade de um efeito de "fortalecimento" do sistema imune, talvez seja interessante esta utilização, mesmo em animais saudáveis.

\section{Referências}

ALEEM, E. $\beta$-Glucans and their applications in cancer therapy: focus on human studies. Anti-Cancer Agents in Medicinal Chemistry, Amsterdam, v. 13, n. 5, p. 709-719, jun. 2013.

AMBRÓSIO, C. L. B.; CAMPOS, F. A. C. S.; FARO, Z. P. Carotenóides como alternativa contra a hipovitaminose A. Revista de Nutrição, Campinas, v. 19, n. 2, p. 233243, mar./abr. 2006.

AOI, W.; NAITO, Y.; SAKUMA, K.; KUCHIDE, M.; TOKUDA, H.; MAOKA, T.; TOYOKUNI, S.; OKA, S.; YASUHARA M.; YOSHIKAWA,T. Astaxanthin limits exercise-induced skeletal and cardiac muscle damage in mice. Antioxidants \& Redox Signaling, Larchmont, v. 5, n. 1, p. 139-144, fev. 2003.

AQUINO, A. A.; SAAD, F. M. O. B.; SANTOS, J. P. F.; ALVES, M. P.; FERRAZZA, R. A.; MIRANDA, M. C. M. G. Efeitos do extrato da parede de levedura na digestibilidade, no escore fecal e na palatabilidade de dietas para gatos. Arquivo Brasileiro de Medicina Veterinária e Zootecnia, Belo Horizonte, v. 62, n. 3, p. 622-630, 2010.

ARAÚJO, J. M. A. Química de alimentos: teoria e prática. 2. ed. Viçosa: Editora UFV, Universidade Federal de Viçosa, 2001.

ASSOCIATION OF AMERICAN FEED CONTROL OFFICIALS - AAFCO. Dogs and cats nutrient profiles. In: AAFCO official publication. Washington, D.C: AAFCO, 2010. p. 169-183.

BARROS, M. P.; PINTO, E.; COLEPICOLO, P.; PEDERSEN, M. Astaxanthin and peridinin inhibit oxidative damage in $\mathrm{Fe}(2+)$-loaded liposomes: scavenging oxyradicals or changing membrane permeability. Biochemical and Biophysical Research Communications, New York, v. 288, n. 1, p. 225-232, out. 2001.

BAUER, J. E. Therapeutic use of fish oils in companion animals. Journal of the American Veterinary Medical Association, Ithaca, v. 239, n. 11, p. 1441-1451, dez. 2011.

BAUMBER, J.; BALL, B. A.; GRAVANCE, C. G.; MEDINA, V.; DAVIES-MOREL, M. C. THE effect of reactive oxygen species on equine motility, viability, acrosomal integrity, mitochondrial membrane potencial, and membrane lipid peroxidation. Journal of Andrology, Philadelphia, v. 21, n. 6, p. 895-902, 2000.

BEHERA, S. K.; DIMRI, U.; SINGH, S. K.; MOHANTA, R. K. The curative and antioxidative efficiency of ivermectin and ivermectin + vitamin E-selenium treatment on canine Sarcoptes scabiei infestation. Veterinary Research Communications, Amsterdam, v. 35, n. 4, p. 237-244, abr. 2011.

BENNEDSEN, M.; WANG, X.; WILLEN, R.; WADSTROM, T.; ANDERSEN, L. P. Treatment of H. pylori infected mice with antioxidant astaxanthin reduces gastric inflammation, bacterial load and modulates cytokine release by splenocytes. Immunology Letters, Amsterdam, v. 70, n. 3, p. 185-189, dez. 1999.

BEYNEN, A. C.; LEGERSTEE, E. Influence of dietary beta-1,3/1,6-glucans on clinical signs of canine osteoarthritis in a double-blind, placebo-controlled trial. American Journal of Animal and Veterinary Sciences, New York, v. 5, n. 2, p. 97-101, set. 2010.

BIAN, Q.; GAO, S.; ZHOU, J.; QIN, J.; TAYLOR, A.; JOHNSON, E. J.; TANG, G.; SPARROW, J. R.; GIERHART, D.; SHANG, F. Lutein and zeaxanthin supplementation reduces photooxidative damage and modulates the expression of inflammation-related genes in retinal pigment epithelial cells. Free Radical Biology and Medicine, New York, v. 53, n. 6, p. 1298-1307, set. 2012.

BIGGS, P.; PARSONS, C. M.; FAHEY, G. C. The Effects of several oligosaccharides on growth performance, nutrient digestibilities, and cecal microbial populations in young chicks. Poultry Science, Oxford, v. 86, n. 11, p. 2327-2336, nov. 2007.

BOND, R.; LLOYD, D. H. Combined treatment with concentrated essential fatty acids and prednisolone in the management of canine atopy. Veterinary Record, London, v. 134, n. 2, p. 30-32, jan. 1994.

BOOTH, N. C.; McDONALD, L. E. Farmacologia e terapêtica em veterinária. Rio de Janeiro: Guanabara Koogan, 1992. 997 p. 
BOOTHE, D. M. Nutraceuticals in veterinary medicine, part 1: definitions and regulations. Compendium on Continuing Education for the Practicing Veterinarian, New York, v. 19, n. 11, p. 1248-1255, jan. 1997.

BROWER, V. Nutraceuticals: poised for a healthy slice of the healthcare market? Nature biotechnology, New York, v. 16, n. 8, p. 728-731, ago. 1998.

BROWN, L.; RIMM, E. B.; SEDDON, J. M.; GIOVANNUCCI, E. L.; CHASAN-TABER, L.; SPIEGELMAN, D.; WILLETT, W. C.; HANKINSON, S. E. A prospective study of carotenoid intake and risk of cataract extraction in US men. The American Journal of Clinical Nutrition, Bethesda, v. 70, n. 4, p. 517-524, out. 1999.

BROWN, S. A.; BROWN, C. A.; CROWELL, W. A.; BARSANTI, J. A.; ALLEN, T., COWELL, C.; FINCO, D. R. Beneficial effects of chronic administration of dietary omega-3 polyunsaturated fatty acids in dogs with renal insufficiency. Journal of Laboratory and Clinical Medicine, St. Louis, v. 131, n. 5, p. 447-455, maio 1998.

CALABRO, S.; CARCIOFI, A. C.; MUSCO, N.; TUDISCO, R.; GOMES, M. O. S.; CUTRIGNELLI, M. I. Fermentation characteristics of several carbohydrate sources for dog diets using the in vitro gas production technique. Italian Journal of Animal Science, Pavia, v. 12, n. 1, p. 21-27, jan. 2013.

CALDER, P. C. The relationship between the fatty acid composition of immune cells and their function. Prostaglandins Leukotrienes \& Essential Fatty Acids, Edinburgh, v. 79, n. 3-5, p. 101-108, set./nov. 2008.

CARCIOFI, A. C.; BAZOLLI, R. S.; PRADA, F. Ácidos graxos poliinsaturados n3 e n6 na alimentação de cães e gatos. Revista de Educação Continuada do CRMV-SP, São Paulo, v. 5, n. 3, p. 268-277, jan. 2002.

CARCIOFI, A. C.; GOMES, M. O. S. Dietary effects on gastrointestinal microbiota of aging dogs: potential tools to health improvement. In: PROCEEDINGS OF THE COMPANION ANIMAL NUTRITION SUMMIT - FOCUS ON GERONTOLOGY, 2010, Clearwater. Proceedings... Clearwater, 2010. p. 62-67.

CASTRO, I. A. Desenvolvimento de alimentos funcionais. Disponível em: <http://people.ufpr.br/ erscta8/ FUNCIONAIS.pdf $>$. Acesso em: 10 set. 2013.

CAVALHEIRO, R.; RÖRIG, L.; FONTANA, J. D.; PESSATTI, M. Testes preliminares de crescimento com uma cepa da microalga produtora de astaxantina Haematococcus Pluvialis (Chlorophyceae, Volvocales). Notas técnicas Facimar, Itajaí, v. 3, n. 1, p. 73-77, jan. 1999.
CHASAN-TABER, L.; WILLETT, W. C.; SEDDON, J. M.; STAMPFER, M. J.; ROSNER, B.; COLDITZ, G. A.; SPEIZER, F. E.; HANKINSON, S. E. A prospective study of carotenoid and vitamin A intakes and risk of cataract extraction in US women. American Journal of Clinical Nutrition, Bethesda, v. 70, n. 4, p. 509-516, out. 1999.

CHEW, B. P.; MATHISON, B. D.; HAYEK, M. G.; MASSIMINO, S.; REINHART, G. A.; PARK, J. S. Dietary astaxanthin enhances immune response in dogs. Veterinary Immunology and Immunopathology, Amsterdam, v. 140, n. 3-4, p. 199-206, abr. 2011.

CHEW, B. P.; PARK, J. S. Carotenoid action on the immune response. Journal of Nutrition, Bethesda, v. 134, n. 1, p. 257S-261S, jan. 2004.

CHEW, B. P.; PARK, J. S.; WONG, T. S.; KIM, H. W.; WENG, B. B.; BYRNE, K. M.; HAYEK, M. G.; REINHART, G. A. Dietary beta-carotene stimulates cellmediated and humoral immune response in dogs. Journal of Nutrition, Bethesda, v. 130, n. 8, p. 1910-1913, ago. 2000.

CHEW, B. P.; WONG, M. W.; WONG, T. S. Effects of lutein from marigold extract on immunity and growth of mammary tumors in mice. Anticancer Research, Athens, v. 16, n. 16B, p. 3689-3694, nov./dez. 1996.

COMHAIRE, F. H.; MAHMOUD, A. M.; DEPUYDT, C. E.; ZALATA, A. A.; CHRISTOPHE, A. B. Mechanisms and effects of male genital tract infection on sperm quality and fertilizing potential: the andrologyst's viewpoint. Human Reproduction Update, Oxford, v. 5, n. 5, p. 395398, set./out. 1999.

CROSS, G.G.; JENNINGS, H. J.; WHITFIELD, D. M.; PENNEY, C. L.; ZACHARIE, B.; GAGNON, L. Immunostimulant oxidized $\beta$-glucan conjugates. International Immunopharmacology, Amsterdam, v. 1, n. 3, p. 539-550, mar. 2001.

DEVARAJ, S.; TANG, R.; ADAMS-HUET, B.; HARRIS, A.; SEENIVASAN, T.; DE LEMOS, J. A.; JIALAL, I. Effect of high-dose $\alpha$-tocopherol supplementation on biomarkers of oxidative stress and inflammation and carotid atherosclerosis in patients with coronary artery disease. American Journal of Clinical Nutrition, Bethesda, v. 86, n. 5, p. 1392-1398, nov. 2007.

DOMONKOS, I.; KIS, M.; GOMBOS, Z.; UGHY, B. Carotenoids, versatile components of oxygenic photosynthesis. Progress in Lipid Research, Oxford, v. 52, n. 4, p. 539-561, out. 2013.

DUNBAR, B. L.; BAUER, J. E. Conversion of essential fatty acids by delta 6-desaturase in dog liver microsomes. Journal of Nutrition, Bethesda, v. 132, n. 6, p. 1701S-1703S, jun. 2002. 
DWYER, J. H.; NAVAB, M.; DWYER, K. M.; HASSAN, K.; SUN, P.; SHIRCORE, A.; HAMA-LEVY, S.; HOUGH, G.; WANG, X.; DRAKE, T.; MERZ, C. N.; FOGELMAN, A. M. Oxygenated carotenoid lutein and progression of early atherosclerosis: the Los Angeles atherosclerosis study. Circulation, Dallas, v. 103, n. 24, p. 2922-2927, jun. 2001.

FREEMAN, L. M. Beneficial effects of omega-3 fatty acids in cardiovascular disease. Journal of Small Animal Practice, Malden, v. 51, n. 9, p. 462-470, jul. 2010.

FREEMAN, L. M.; RUSH, J. E.; KEHAYIAS, J. J.; ROSS JUNIOR, J. N.; MEYDANI, S. N.; BROWN, D. J.; DOLNIKOWSKI, G. G.; MARMOR, B. N.; WHITE, M. E.; DINARELLO, C. A.; ROUBENOFF, R. Nutritional alterations and the effect of fish oil supplementation in dogs with heart failure. Journal of Veterinary Internal Medicine, Philadelphia, v. 12, n. 6, p. 440-448, nov./dez. 1998.

GOMES, M. O. S. Efeito da adição de parede celular de levedura sobre a digestibilidade, microbiota, ácidos graxos de cadeia curta e aminas fecais e parâmetros hematológicos e imunológicos de cães. 2009. Dissertação (Mestrado em Medicina Veterinária) - Faculdade de Ciências Agrárias e Veterinárias. Universidade Estadual Paulista, Jaboticabal.

GRIESHOP, C. M.; FLICKINGER, E. A.; BRUCE, K. J.; PATIL, A. R.; CZARNECKI-MAULDEN, G. L.; FAHEY JUNIOR, G. C. Gastrointestinal and immunological responses of senior dogs to chicory and mannan-oligosaccharides. Archives of Animal Nutrition, Abingdon, v. 58, n. 6, p. 483-493, dez. 2004.

HALADOVÁ, E.; MOJŽIŠOVÁ, J.; SMRČO, P.; ONDREJKOVÁ, A.; VOJTEK, B.; HIPÍKOVÁ, V. The effect of $\beta(1,3 / 1,6) d$-glucan on selected non-specific and specific immunological parameters in dogs after vaccination. Folia Veterinaria, Košice, v. 53, n. 1, p. 4346, jan. 2009

HAND, M. S.; THATCHER, C. D.; REMILLARD, R. L.; ROUDEBUSH, P.; NOVOTNY, B. J. Small animal clinical nutrition. 5. ed. Topeka, KS: Mark Morris Institute, 2010. 1314 p.

HARVEY, R. G. Management of feline miliary dermatitis by supplementing the diet with essential fatty acids. Veterinary Record, London, v. 128, n. 14, p. 326-329, abr. 1991.

HEATON, P. R.; REED, C. F.; MANN, S. J.; RANSLEY, R.; STEVENSON, J.; CHARLTON, C. J.; SMITH, B. H.; HARPER, E. J.; RAWLINGS, J. M. Role of dietary antioxidants to protect against DNA damage in adult dogs. The Journal of Nutrition, Bethesda, v. 132, n. 6, p. 1720-1724, jun. 2002.
HUGHES, D. A. Effects of carotenoids on human immune function. Proceedings of the Nutrition Society, London, v. 58, n. 3, p. 713-718, ago. 1999.

HUNTER JUNIOR, K. W.; GAULT, R. A.; BERNER, M. D. Preparation of microparticulate beta-glucan from Saccharomyces cerevisiae for use in immune potentiation. Letters in Applied Microbiology, Reno, v. 35, n.4, p. 267-271, out. 2002.

JEWELL, D. E.; TOLL, P. W.; WEDEKIND, K. J.; ZICKER, S. C. Effect of increasing dietary antioxidants on concentrations of vitamin $\mathrm{E}$ and total alkenals in serum of dogs and cats. Veterinary Therapeutics: Research in Applied Veterinary Medicine, Trenton, v. 1, n. 4, p. 264272, jan. 2000.

KAPUN A. P.; SALOBIR, J.; LEVART, A.; KALCHER G. T.; SVETE, A. N.; KOTNIK, T. Plasma and skin vitamin $\mathrm{E}$ concentrations in canine atopic dermatitis. Veterinary Quarterly, Amsterdam, v. 33, n. 1, p. 2-6, jan. 2013.

KIM, H. W.; CHEW, B. P.; WONG, T. S.; PARK, J. S.; WENG, B. B.; BYRNE, K. M.; HAYEK, M. G.; REINHART, G. A. Modulation of humoral and cell-mediated immune responses by dietary lutein in cats. Veterinary Immunology and Immunopathology, Amsterdam, v. 73, n. 3-4, p. 331-341, mar. 2000a.

KIM, H. W.; CHEW, B. P.; WONG, T. S.; PARK, J. S.; WENG, B. B.; BYRNE, K. M.; HAYEK, M. G.; GREGORY, A. Dietary lutein stimulates immune response in the canine. Veterinary Immunology and Immunopathology, Amsterdam, v. 74, n. 3-4, p. 315-327, maio 2000b.

KOGAN, G.; KOCHER, A. Role of yeast cell wall polysaccharides in pig nutrition and health protection. Livestock Science, Amsterdam, v. 109, n. 1-3, p. 161-165, maio 2007.

KVANSAKUL， J.; RODRIGUEZ-CARMONA, M.; EDGAR, D. F.; BARKER, F. M.; KÖPCKE, W.; SCHALCH, W.; BARBUR, J. L. Supplementation with the carotenoids lutein or zeaxanthin improves human visual performance. Ophthalmic and Physiological Optics, Oxford, v. 26, n. 4, p. 362-371, jul. 2006.

LIPKE, P. N.; OVALLE, R. Cell wall architecture in yeast: new structure and new challenges. Journal of Bacteriology, Baltimore, v. 180, n. 15, p. 3735-3740, ago. 1998.

LOGAS, D.; KUNKLE, G. A. Double-blinded crossover study with marine oil supplementation containing high dose eicosapentaenoic acid for the treatment of canine pruritic skin disease. Veterinary Dermatology, Oxford, v. 5, n. 3, p. 99-104, set. 1994. 
MANTOVANI, M.S.; BELLINI, M. F.; ANGELI, J. P.; OLIVEIRA, R. J.; SILVA, A. F.; RIBEIRO, L. R. Beta-Glucans in promoting health: Prevention against mutation and cancer. Mutation Research, Amsterdam, v. 658, n. 3, p. 154-161, mar./abr. 2008.

MARANGON, K.; DEVARAJ, S.; TIROSH, O.; PACKER, L.; JIALAL, I. Comparison of the effect of alpha-lipoic acid and alpha-tocopherol supplementation on measures of oxidative stress. Free Radicals Biology and Medicine, New York, v. 27, n. 9-10, p. 1114-1121, nov. 1999.

MASSIMINO S.; KEARNS, R. J.; LOOS, K. M.; BURR, J. Effects of age and dietary beta-carotene on immunological variables in dogs. Journal of Veterinary Internal Medicine, v. 17, n. 6, p. 835-842, nov./dez. 2003.

MEDZHITOV, R.; JANEWAY JUNIOR, C. Innate immunity. The New England Journal of Medicine, Boston, v. 343, n. 5, p. 338-344, ago. 2000.

MIDDELBOS, I. S.; FASTINGER, N. D.; FAHEY JUNIOR, G. C. Evaluation of fermentable oligosaccharides in diets fed to dogs in comparison to fiber standards. Journal of Animal Science, Champaign, v. 85 , n. 11 p. 3033-3044, nov. 2007.

MIDDELBOS, I. S.; GODOY, M. R.; FASTINGER, N. D.; FAHEY JUNUOR, G. C. A dose-response evaluation of spray-dried yeast cell wall supplementation of diets fed to adult dogs: effects on nutrient digestibility, immune indices, and fecal microbial populations. Journal of Animal Science, Champaign, v. 85, n. 11, p. 3022-3032, nov. 2007.

MILLER, W. H.; SCOTT, D. W.; WELLINGTON, J. R. Treatment of dog with hip arthritis with a fatty acid supplement. Canine Practice, New York, v. 7, n. 6. p. 6-8, jan. 1992.

MORALES-LÓPEZ, R.; AUCLAIR, E.; VAN IMMERSEEL, F.; DUCATELLE, R.; GARCÍA, F.; BRUFAU, J. Effects of different yeast cell wall supplements added to maize- or wheat-based diets for broiler chickens. British Poultry Science, London, v. 51, n. 3, p. 399-408, jun. 2010.

NATIONAL RESEARCH COUNCIL - NRC. Nutrient requirements of dogs and cats. Washington: National Academy, 2006. 398 p.

NOCHTA, I.; TUBOLY, T.; HALAS, V.; BABINSZKY, L. Effect of different levels of mannan-oligosaccharide supplementation on some immunological variables in weaned piglets. Journal of Animal Physiology and Animal Nutrition, Berlin, v. 93, n. 4, p. 496-504, ago. 2009.
PARK, J. S.; CHEW, B. P.; WONG, T. S. Dietary lutein from marigold extract inhibits mammary tumor development in BALB/c mice. Journal of Nutrition, Bethesda, v. 28, n. 10, p. 1650-1656, out. 1998.

PARK, J. S.; CHYUN, J. H.; KIM, Y. K.; LINE, L. L.; CHEW, B. P. Astaxanthin decreased oxidative stress and inflammation and enhanced imune response in humans. Nutrition \& Metbolism, London, v. 7, n. 18, p. 1-10, mar. 2010a.

PARK, J. S.; KIM, H. W.; MATHISON, B. D.; HAYEK, M. G.; MASSIMINO, S.; REINHART, G. A.; Astaxanthin uptake in domestic dogs and cats. Nutrition \& Metabolism, London, v. 7, n. 52, p. 1-8, jun. 2010 b.

PARK, J. S.; MATHISON, B. D.; HAYEK, M. G.; MASSIMINO, S.; REINHART, G. A.; CHEW, B. P. Astaxanthin stimulates cell-mediated and humoral immune responses in cats. Veterinary Immunology and Immunopathology, Amsterdam, v. 144, n. 3-4, p. 455461, dez. 2011.

PHAM-HUY, L. A.; HE, H.; PHAM-HUY, C. Free radicals, antioxidants in diseases and health. International Journal of Biomedical Science, Pomona, v. 4, n. 2, p. 8996, jun. 2008.

REINHART, G. A. Canine dietary fatty acid ratio and tissue eicosanoid production. In: AMERICAN COLLEGE OF VETERINARY INTERNAL MEDICINE, 13., ANNUAL VETERINARY MEDICAL FORUM, 1995, Florida. Proceedings...Florida: ACVIM, 1995. p. 22-25.

ROUSH, J. K.; DODD, C. E.; FRITSCH, D. A.; ALLEN, T. A.; JEWELL, D. E.; SCHOENHERR, W. D.; RICHARDSON, D. C.; LEVENTHAL, P. S.; HAHN, K. A. Multicenter veterinary practice assessment of the effects of omega-3 fatty acids on osteoarthritis in dogs. Journal of the American Veterinary Medical Association, Ithaca, v. 236, n. 1, p. 59-66, jan. 2010.

RUIZ-HERRERA, J. Fungal cell wall: structure, synthesis, and assembly. Boca Raton, EUA: CRC Press, 1992.

RYCHLIK, A.; NIERADKA, R.; KANDER, M.; NOWICKI, M.; WDOWIAK, M.; KOŁODZIEJSKASAWERSKA, A. The effectiveness of natural and synthetic immunomodulators in the treatment of inflammatory bowel disease in dogs. Acta Veterinaria Hungarica, Budapest, v. 61, n. 3, p. 297-308, set. 2013.

SANTOS, M. S.; MEYDANI, S. N.; LEKA, L.; WU, D.; FOTOUHI, N.; MEYDANI, M.; HENNEKENS, C. H.; GAZIANO, J. M. Natural killer cell activity in elderly men is enhanced by beta-carotene supplementation. American Journal of Clinical Nutrition, Bethesda, v. 64, n. 5, p. 772-777, nov. 1996. 
SCARFF, D. H.; LLOYD, D. H. Double blind, placebocontrolled, crossover study of evening primrose oil in the treatment of canine atopy. Veterinary Record, London, v. 131, n. 5, p. 97-99, ago. 1992.

SCHENCK, P. A. Canine hyperlipidemia: causes and nutritional management. In: PIBOT, P.; BIOURGE, V.; ELLIOTT, D. (Ed.). Encyclopedia of canine clinical nutrition. Aimargues: Aniwa SAS-Royal Canin, 2006. p. 222-245.

SCOTT, D. W.; MILLER JUNIOR, W. H.; REINHART, G. A.; MOHAMMED, H. O.; BAGLADI, M. S. Effect of an omega-3/omega-6 fatty acid-containing commercial lamb and rice diet on pruritus in atopic dogs: results of a single-blinded study. Canadian Journal of Veterinary Research, Ottawa, v. 61, n. 2, p. 145-153, abr. 1997.

SHANMUGAM, S.; PARK, J. H.; KIM, K. S.; PIAO, Z. Z.; YONG, C. S.; CHOI, H.; WOO, J. S. Enhanced bioavailability and retinal accumulation of lutein from self-emulsifying phospholipid suspension (SEPS). International Journal of Pharmaceutics, Amsterdam, v. 412, n. 1-2, p. 99-105, jun. 2011.

SIMOPOULOS, A. P. Omega-3 polyunsaturated. In: CABALlERO, B.; ALLEN, L.; PRENTICE, A. (Ed.). Encyclopaedia of human nutrition. Oxford, UK: Elsevier, 2005. p. 205-219.

STAHL, W.; HEINRICH, U.; JUNGMANN, H.; SIES, H.; TRONNIER, H. Carotenoids and carotenoids plus vitamin $\mathrm{E}$ protect against ultraviolet light-induced erythema in humans. American Journal of Clinical Nutrition, Bethesda, v. 71, n. 3, p. 795-8, mar. 2000.

STAHL, W.; SIES, H. Antioxidant activity of carotenoids. Molecular Aspects of Medicine, Oxford, v. 24, n. 6, p. 345-351, dez. 2003.

STRICKLING, J. A.; HARMON, D. L.; DAWSON, K. A.; GROSS, K. L. Evaluation of oligosaccharide addition to dog diets: Influences on nutrient digestion and microbial populations. Animal Feed Science and Technology, Amsterdam, v. 86, n. 3-4, p. 205-219, ago. 2000.

STUYVEN, E.; VERDONCK, F.; VAN HOEK, I.; DAMINET, S.; DUCHATEAU, L.; REMON, J. P.; GODDEERIS, B. M.; COX, E. Oral administration of beta-1,3/1,6-glucan to dogs temporally changes total and antigen 1 specific IgA and IgM. Clinical and Vaccine Immunology, Washington, v. 17, n. 2, p. 281-285, fev. 2010.

SUMANTRAN, V. N.; ZHANG, R.; LEE, D. S.; WICHA, M. S. Differential regulation of apoptosis in normal versus transformed mammary epithelium by lutein and retinoic acid. Cancer Epidemiology, Biomarkers and Prevention, Philadelphia, v. 9, n. 3, p. 257-263, mar. 2000.

SWANSON, K. S.; GRIESHOP, C. M.; FLICKINGER, E. A.; BAUER, L. L.; HEALY, H. P.; DAWSON, K. A.; MERCHEN, N. R.; FAHEY JUNIOR, G. C. Supplemental fructooligosaccharides and mannanoligosaccharides influence immune function, ileal and total tract nutrient digestibilities, microbial populations and concentration of protein catabolites in the large bowel of dogs. Journal of Nutrition, Bethesda, v. 132, n. 5, p. 980-989, maio $2002 \mathrm{a}$.

Effects of supplemental fructooligosaccharides and mannanoligosaccharides on colonic microbial populations, immune function and fecal odor components in the canine. Journal of Nutrition, Bethesda, v. 132, n. 1, p. 1717S-1719S, jun. 2002b.

TLASKALOVÁ-HOGENOVÁ, H.; TUCKOVÁ, L.; LODINOVÁ-ZÁDNIKOVÁ, R.; STEPÁNKOVÁ, R.; CUKROWSKA, B.; FUNDA, D. P.; STRIZ, I.; KOZÁKOVÁ, H.; TREBICHAVSKÝ, I.; SOKOL, D.; REHÁKOVÁ, Z.; SINKORA, J.; FUNDOVÁ, P.; HORÁKOVÁ, D.; JELÍNKOVÁ, L.; SÁNCHEZ, D. Mucosal immunity: its role in defense and allergy. International Archives of Allergy and Immunology, Basel, v. 128, n. 2, p. 77-89, jun. 2002.

TORREJON, C.; JUNG, U. J.; DECKELBAUM, R. J. n-3 Fatty acids and cardiovascular disease: actions and molecular mechanisms. Prostaglandins Leukotrienes \& Essential Fatty Acids, Edinburgh, v. 77, n. 5-6, p. 319326, nov./dez. 2007.

TRABER, M. G.; RADER, D.; ACUFF, R. V.; RAMAKRISHNAN, R.; BREWER, H. B.; KAYDEN, H. J. Vitamin E dose-response studies in humans with use of deuterated RRR-alpha-tocopherol. American Journal of Clinical Nutrition, Bethesda, v. 68, n. 4, p. 847-53, out. 1998.

TREVIZAN, L.; KESSLER, A. M. Lipídeos na nutrição de cães e gatos: metabolismo, fontes e uso em dietas práticas e terapêuticas. Revista Brasileira de Zootecnia, Brasília, v. 38, n. 1, p. 15-25, 2009.

TWEDT, D. C.; WEBB, C. B.; TETRICK, M. A. The effect of dietary vitamin $\mathrm{E}$ on the clinical laboratory and oxidant status of dogs with chronic hepatitis. Journal of Veterinary Internal Medicine, Philadelphia, v. 17, n. 3, p. 418A, 2003.

VANDEWEERD, J-M.; CAMBIER, C.; GUSTIN, P. Nutraceuticals for canine liver disease: assessing the evidence. The Veterinary clinics of North America. Small Animal Practice, Philadelphia, v. 43, n. 5, p. 1171-1179, set. 2013. 
VAUGHN, D. M.; REINHART, G. A.; SWAIM, S. F.; LAUTEN, S. D.; GARNER, C. A.; BOUDREAUX, M. K.; SPANO, J. S.; HOFFMAN, C. E.; CONNER, B. Evaluation of effects of dietary n-6 to n-3 fatty acid ratios on leukotriene B synthesis in dog skin and neutrophils. Veterinary Dermatology, Oxford v. 5, n. 4, p. 163-173, dez. 1994.

VERBRUGGHE, A.; JANSSENS, G. P. J.; ROCHUS, K.; PAAP, P. M.; VERHAERT, L.; POLIS, I.; COX, E.; PETERS, I.; HESTA, M. B-1,3/1,6-glucans downregulate whole blood $\mathrm{NF} \kappa \mathrm{B}$ and IL-1 $\beta$ mRNA expression and alveolar bone loss in feline periodontal disease. In: CONGRESS OF THE EUROPEAN SOCIETY OF VETERINARY AND COMPARATIVE NUTRITION, 16., 2012, Bydgoszcz. Proceedings... Bydgoszcz: ESVCN, 2012. p. 52-52.

VETVICKA, V.; VASHISHTA, A.; SARASWATOHRI, S.; VETVICKOVA, J. Immunological effects of yeast- and mushroom-derived beta-glucans. Journal of Medicinal Food, Larchmont, v. 11, n. 4, p. 615-622, dez. 2008.

WEITBERG, A. B. A phase I/II trial of beta- $(1,3) /(1,6)$ D-glucan in the treatment of patients with advanced malignancies receiving chemotherapy. Journal of Experimental \& Clinical Cancer Research, Roma, v. 27, n. 40, p. 1-4, set. 2008.

WENG, C.; CHEW, B. P.; WONG, T. S.; PARK, J. S.; KIM, H. W.; LEPINE, A. J. Beta-carotene uptake and changes in ovarian steroids and uterine proteins during the estrous cycle in the canine. Journal of Animal Science, Champaign, v. 78, n. 5, p. 1284-1290, maio 2000.
WHELAN, K. Mechanisms and effectiveness of prebiotics in modifying the gastrointestinal microbiota for the management of digestive disorders. The Proceedings of the Nutrition Society, London, v. 72, n. 3, p. 288-298, ago. 2013.

WHITE, L. A.; NEWMAN, M. C.; CROMWELL, G. L.; LINDEMANN, M. D. Brewers dried yeast as a source of mannan oligosaccharides for weanling pigs. Journal of Animal Science, Champaign, v. 80, n. 10, p. 2619-2628, out. 2002.

YANG, Y.; IJI, P. A.; KOCHER, A.; THOMSON, E.; MIKKELSEN, L. L.; CHOCT, M. Effects of mannanoligosaccharide in broiler chicken diets on growth performance, energy utilization, nutrient digestibility and intestinal microflora. British Poultry Science, Edinburgh, v. 49, n. 2, p. 186-194, mar. 2008.

ZAINE, L. Avaliação do efeito de derivados de parede celular de levedura de cana-de-açúcar (Saccharomyces cerevisiae) sobre a resposta imune de cães adultos. 2010. Dissertação (Mestrado em Medicina Veterinária) - Faculdade de Ciências Agrárias e Veterinárias. Universidade Estadual Paulista, Jaboticabal.

ZALATA, A. A.; DEPUYDT, C. E. White blood cells cause oxidative damage to the fatty acid composition of phospholipids of human spermatozoa. International Journal of Andrology, Copenhagen, v. 21, n. 3 p. 154162, jun. 1998. 
